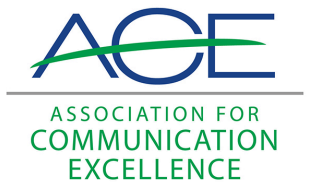

Journal of Applied Communications

\title{
Exploring Science Communication Effectiveness in the U.S. Federal Government Research Process: A Case Study with the U.S. Livestock Producers' Antimicrobial Use Research
}

\author{
Katie Abrams \\ Colorado State University \\ Chelsea Bonser \\ Colorado State University \\ Amber McCord \\ Texas Tech University
}

Follow this and additional works at: https://newprairiepress.org/jac

Part of the Organizational Communication Commons, and the Public Relations and Advertising Commons

cc) (i) (2)

This work is licensed under a Creative Commons Attribution-Noncommercial-Share Alike 4.0 License.

\section{Recommended Citation}

Abrams, Katie; Bonser, Chelsea; and McCord, Amber (2020) "Exploring Science Communication Effectiveness in the U.S. Federal Government Research Process: A Case Study with the U.S. Livestock Producers' Antimicrobial Use Research," Journal of Applied Communications: Vol. 104: Iss. 4. https://doi.org/10.4148/1051-0834.2343

This Research is brought to you for free and open access by New Prairie Press. It has been accepted for inclusion in Journal of Applied Communications by an authorized administrator of New Prairie Press. For more information, please contact cads@k-state.edu. 


\title{
Exploring Science Communication Effectiveness in the U.S. Federal Government Research Process: A Case Study with the U.S. Livestock Producers' Antimicrobial Use Research
}

\begin{abstract}
Several U.S. federal government agencies collect and disseminate scientific data on a national scale to provide insights for agricultural trade, research, consumer health, and policy. Occasionally, such data have potential to provide insights to advance conversations and actions around critical and controversial issues in the broad agricultural system. Such government studies provide evidence for others to discuss, further interpret, and act upon, but to do so, they must be communicated well. When the research intersects with contentious socio-political issues, successful communication not only depends on tactics, but as this study illuminates, it also depends on relationship quality between research producers, study participants, and end-users. USDA's Animal and Plant Health Inspection Service (APHIS) conducted firstof-its kind national studies on cattle and swine producers' use of antimicrobials. The use of antimicrobials in animal agriculture is considered a critical and controversial issue pertaining to antimicrobial resistance. In recognition of the anticipated wide-ranging interests in these studies, APHIS sought to understand stakeholders' perceptions and experiences of the federal government research process and products with aim of improving their science communication and relations. This study reports on findings from in-depth interviews with 14 stakeholders involved in the antimicrobial use studies to make recommendations for improving communication and relations between the agency and its stakeholders. From this research, we draw implications that are transferrable to numerous types of government science communication efforts within agricultural sectors.

Keywords

science communication, antimicrobial use, animal health, relationship quality, knowledge transfer and exchange

\section{Cover Page Footnote/Acknowledgements}

This research was funded in-part by a cooperative agreement from the United States Department of Agriculture Animal and Plant Health Inspection Service. The sponsor was not involved in data analysis or reporting.
\end{abstract}




\section{Introduction}

Several federal agencies collect and disseminate scientific data on a national scale to provide insights for agricultural trade, research, consumer health, and policy. These data have potential to provide insights to advance conversations and actions around critical and controversial issues in the broad agricultural system. Such studies provide evidence for others to discuss, further interpret, and act upon, but to do so, they must be communicated well.

Monitoring animal health on a national level is an important service provided by the United States Department of Agriculture (USDA) National Animal Health Monitoring Service (NAHMS). This program, led by USDA's Animal and Plant Health Inspection Service (APHIS), synthesizes input from other government agencies, livestock producers, academics and industry professionals to conduct national research studies that provide valuable animal health information to animal agriculture stakeholders. These studies, conducted at regular intervals, ensure accurate information is reported to track animal health trends that affect animal welfare, agricultural trade, research, consumer health, and policy (USDA APHIS, 2010). Until recently, one aspect these studies had yet to fully capture was the use of antimicrobials, which includes antibiotics ${ }^{1}$, in animal agriculture production practices. The rise in infectious microorganisms resistant to antimicrobials, termed antimicrobial resistance (AMR), is considered one of the most pressing and serious threats to animal and human health (World Health Organization, 2018). However, in the U.S., data tracking and characterizing antimicrobial use in both humans and animals is insufficient to take well-informed actions (World Health Organization, 2018). Sales figures on antibiotics have been one indicator of use, but such data are of limited value for understanding implications of use (Charles, 2016). Thus, in December 2014, the USDA released an Antimicrobial Resistance Action Plan (USDA APHIS, 2015). Part of this plan included measuring livestock producers' use of antimicrobials, which is what the NAHMS 2017 antimicrobial use (AMU) studies set out to do. Their studies aimed to provide data (not discussion or recommendations) to advance understanding of AMR and inform others to design AMU best practices in livestock production.

The NAHMS 2017 AMU studies coincidentally came on the heels of the new Food and Drug Administration (FDA) Veterinary Feed Directive regulations and guidance aimed at limiting medically important antimicrobials to disease treatment, control, and prevention and requiring additional veterinary oversight and documentation (U.S. FDA, 2017). These regulatory actions were cautiously lauded by human health advocates with some reservations as to whether the actions go far enough (see PEW, 2016) and accepted by animal pharmaceutical companies and most producers as having a neutral or positive impact (Farm Foundation, 2016). Beef producers indicated they are willing to share their management practices but do not believe their operations contribute to AMR (Lee et al., 2017).

Consumers have varying degrees of acceptance of AMU in animal agriculture. Consumers and the general public are more keyed in on antibiotics, and as such even those within the industry

\footnotetext{
1 “Antimicrobials are products that kill microorganisms or keep them from multiplying (reproducing) or growing. They can be either naturally occurring or synthetic (manmade) and are most commonly used to prevent, control, or treat diseases and infections caused by microorganisms. Antibiotics are antimicrobials that can kill bacteria or inhibit their growth or reproduction. All antibiotics are antimicrobials, but not all antimicrobials are antibiotics." (American Veterinary Medical Association, 2020, para. 5, 7)
} 
are more likely to mainly focus on antibiotics as well. A consumer survey showed $22 \%$ ranked antibiotics among their top three food safety concerns, and $74 \%$ supported using antibiotics in sick animals with caveats that there is a sufficient withdrawal period $(47 \%)$ or that they never enter the food system (27\%) (International Food Information Council Foundation, 2016). In sum, while human health advocates push for more government oversight of AMU in animal agriculture, livestock producers do not believe their use to be a major issue in AMR. Combined with consumers' ambivalence toward AMU in animal agriculture, the complexity of AMU and AMR in both the human and animal health realm continues to be a point of contention. With the variety of stakeholders interested in this kind of data, the complexity of AMU and AMR, and the sociopolitical controversy surrounding antimicrobials in animal agriculture, successfully communicating the NAHMS AMU studies and other future studies like it is of critical importance. This study, therefore, provides an examination of the science communication process and products through the lens of key stakeholders for the NAHMS AMU studies.

\section{Literature Review}

The AMU study reports consists of descriptive numerical data on swine and cattle producers' use of antimicrobials that was collected via confidential surveys. It includes data on the types of antimicrobials used, duration of use, how antimicrobials were administered, and site demographics (USDA, 2019a, USDA, 2019b). Given the scientific nature of the AMU study and the contentious nature of the topic itself, literature on communicating scientific uncertainty is most relevant.

Communicating aspects related to scientific uncertainty are particularly important when the science deals with a controversial issue like antimicrobial use and resistance. Communicating uncertainty is related to perceptions of transparency in the process, which can foster trust (Johnson \& Slovic, 1995) and help decision makers weigh risks (Joslyn \& LeClerc, 2012). With controversial issues, a rich body of literature illustrates how some stakeholders and individuals will leverage scientific uncertainty "to protect their economic interests or ideological preferences" (National Academies of Sciences, Engineering, and Medicine, 2017, p. 61). Such efforts can detour scientific understanding, but more light is being brought to such strategies and the existence of media "echo chambers" among the public. Druckman (2015) contends that explaining how studies were developed, data collected, and conclusions reached can build audiences' credibility perceptions about the science and increase their interest in scientific discovery. To decrease the uncertainty surrounding AMU data and facilitate relationships based on trust and transparency, two conceptual frameworks and literature on relational quality served as a foundation for this study. Specifically, Knowledge Transfer and Exchange (KTE), Knowledge Transfer and Translation (KTT) and organizational-stakeholder relationship quality and trust provided a guide for this research with an aim to provide initial recommendations for communicating the study.

\section{Knowledge Transfer and Exchange}

The KTE is a research information dissemination process between research producers and users (Smith, 2014). This framework emerged as communication research evolved to show that knowledge exchange was much more than just a one-way effort. KTE explains that partnerships in research efforts that include research producers, decision-makers, stakeholders, and research 
end-users are extremely effective in increasing the likelihood of research evidence being used in practice or policy (Lavis et al,, 2003). KTE advocates the importance of including these partnerships early on in the research process in order to overcome barriers that may occur. The idea behind this is that researchers and stakeholders will be on the same page throughout the research process, gaining a better understanding of expectations and view research as a process instead of simply a product (Smith, 2014). Trust among all parties is a major pinnacle in this model, which takes many positive shared experiences between groups. Knowledge transfer efforts are successful through ongoing communication efforts that include and address industry or community issues that ultimately are incorporated into decision-making (Smith, 2014).

\section{Knowledge Translation and Transfer}

Another framework that takes knowledge transfer a step further, is Knowledge Translation and Transfer (KTT). This framework is similar to KTE but accelerates the "transformation of knowledge into use through synthesis, exchange, dissemination, dialogue, collaboration, and brokering among researchers and research users" (Ontario, 2016, para.1). This framework is successfully used by the Ontario Ministry of Agriculture, Food and Rural Affairs to reach stakeholders in Canadian agriculture and accelerate the transfer of knowledge through research.

Ontario (2016) illustrates how KTT focuses on a stakeholder needs-based approach and takes into account demand for research topics. This framework breaks down its efforts into three groups, including program, policy, and commercialization research. Program research is research designed to improve a program through audiences of that particular value chain (e.g. animal agriculture), while policy research attempts to answer important questions needed for policy development. Commercialization research applies to development or improvement of a commercial product (such as antimicrobials) that targets organizations that bridge gaps between research and the industry market. Planning a successful KTT effort also emphasizes collaboration, partnerships, and having clear audience channels designed. KTT explains the idea of a "knowledge broker" who helps share and disseminate research among researcher producers and users. This person (or group) designs and decides appropriate information dissemination channels that ultimately build trust between the organization and stakeholders (Ontario, 2016). The Science of Science Communication National Research Agenda summarizes what is currently known about communicating science issues (National Academies of Sciences, Engineering, and Medicine, 2017). The agenda also brings up the notion of knowledge "brokering" and the use of "boundary organizations" to help facilitate the flow of information, as KTT also echoed.

\section{Relationship Quality and Organization-Stakeholder Trust}

As the KTE and KTT frameworks illustrate, effective relationships with key stakeholders throughout the science generation and dissemination process can lead to greater impacts. Relationship quality between an organization and its stakeholders consists of 6 dimensions (Hon \& Grunig, 1999):

Control mutuality: the degree to which parties agree on who has rightful power to influence one another; Trust: one party's level of confidence in and willingness to open oneself to the other; Satisfaction: the extent to which one party feels favorably toward the other because positive expectations about the relationship are reinforced; Commitment: 
extent to which one party believes and feels the relationship is worth spending energy to maintain and promote. Exchange relationship: both parties provide benefits because each has received (or expects to) benefits from the other; and Communal relationship: both parties provide benefits to the other because [of] concern for the other's welfare-even when they get nothing in return. (p. 19-20)

Although trust appears as a mere singular component of relationship quality, arguably, each of these dimensions interplay with one another to shape trust. The concept of trust can be separated into two main types: relational trust and calculative trust (Earle, 2010). Earle synthesized trust literature relevant to risk management to further define its nature. Relational trust, the more resilient of the two, is defined by perceived intentions of the other and shared values. Calculative trust, which is more fragile, is determined by actions and competence. Earle found the majority of research examining the relative importance of the two types shows relational trust to be more important. "Knowing whether the intentions of the other are good or bad (relative to oneself) is more important than knowing what the other can do" (Earle, 2010, p. 542).

The dimensions of relationship quality offer more concrete guidance as to what effects broader feelings of trust between an organization and stakeholders. Although organizational and scientific process transparency is often touted as another key influencer of trust, science communication studies have only shown that transparency is demanded, but may not actually increase positive attitudes (Abrams, Zimbres, \& Carr, 2015) or trust (Frewer et al., 2002). Fairness of a process or outcomes, however, are closely related to trust in science communication (National Academies of Sciences, Engineering, and Medicine, 2017), and fairness seems directly related to the dimensions of relationship quality. That is, if both an organization and stakeholder feels the relationship is fair, other dimensions of relationship quality are likely to be favorable.

A 2018 consumer survey showed federal agencies are held responsible for food safety over any other entity; however, trust in those agencies is low (Center for Food Integrity, 2018). This aligns with research on environmental science communication (Brewer \& Ley, 2013) and Pew Research (2017) polling, showing the federal government to have little trust among about $82 \%$ of general public. This statistic illustrates the importance of equipping other, more trusted entities to serve as those knowledge brokers (referencing back to KTT framework) - who may have their own trust issues as well. However, working with knowledge brokers does not absolve federal agencies of making attempts to improve trust among its other publics.

\section{Summary}

KTE, KTT, and relationship quality and organizational-stakeholder trust provided a framework for creating a study that takes a holistic inquiry of the nature of government-sponsored science communication as not just a product, but as a process. This literature review provides a lens through which to formulate recommendations to better understand and improve the science communication process for government research activities. 


\section{Purpose and Objectives}

The APHIS NAHMS studies, particularly the AMU study, provided a case study through which to explore agricultural stakeholders' perceptions and experiences of the federal government research process and product (i.e., the report) and to formulate recommendations to improve communication and relations among a federal agency and its stakeholders. KTE and KTT frameworks recommend identifying and involving stakeholders throughout the research process to increase the likelihood for research to be used. Specifically, questions such as determining what knowledge and how that knowledge should be transferred are essential to answer (Lavis et. al, 2003). Thus, the first study objective was to describe the AMU studies reports stakeholders' preferences for scientific livestock industry information for eventual use in their communication efforts. Additionally, both the KTE and KTT frameworks illustrate the importance of strong, trusting relationships between the research organization and their stakeholders. Therefore, the second objective was to explore NAHMS stakeholders' perceptions of APHIS and the NAHMS studies (the AMU study, in particular) to characterize organizational-stakeholder relationship quality and identify opportunities to improve relations. This research has implications for the numerous types of government science communication efforts within agricultural sectors.

\section{Methods}

In-depth interviews are a common method used in phenomenological approaches within qualitative inquiry. One of the key benefits of in-depth interviews is they allow for participants' experiences and perceptions to be explored in their own terms without abstract measures and for these descriptions to be further probed and clarified (Marshall \& Rossman, 2014). When it comes to selecting and sampling interview participants, purposive sampling is best suited to identifying individuals who have had experiences relating to the phenomenon to be researched (Robinson, 2013). This was a necessary approach since this study sought to explore experiences pertaining to a particular federal government unit and its research. The interview guide was developed by the first two authors based on the theoretical framework and study objectives. It included questions about how stakeholders receive and seek out scientific livestock industry information and the demands they face for using and re-packaging that information for different audiences. The questioning then focused on their experiences in relationships (current and past) with federal agencies, particularly APHIS; how their own stakeholders view APHIS and the NAHMS studies; barriers to building better relationships; and recommendations for improving relations.

Participants were 14, purposively sampled, representatives from national livestock industry groups $(n=5)$, university extension specialists in animal health $(n=4)$, and national advocacy groups $(n=3)$ supporting AMU as-is, against it, and more neutral, as well as agricultural journalists with one from a pork outlet and another from a cattle outlet $(n=2)$. (Note: Additional details cannot be provided without potentially compromising participants' identities.) All interviewees were responsible for some aspect of communication on behalf of their organization. The research team and representatives from USDA-APHIS deemed these stakeholders to be illustrative of knowledge brokers or boundary organizations who can help facilitate the flow of research information in agriculture. (Note: the USDA-APHIS representatives only provided general input on the types of stakeholders and were not privy to the identities of the individuals selected.) Some of the organizations represented had existing relationships with USDA APHIS to support the 
development of NAHMS studies. All but one extension specialist were aware of NAHMS studies, but not always by name. Participants were assured confidentiality and we clearly delineated our roles as independent researchers to protect the study's integrity and participants' feelings of trust. Interviews were conducted via online audio conference software and lasted about 35 to 60 minutes. The interviewer was accompanied by an assistant who took notes and corroborated key points in an initial debriefing about the discussion that took place. Interviews were transcribed by a transcription services company and then the interviewer along with the lead author coded for key ideas, topical markers, examples, and themes relevant to the objectives using thematic analysis within one month of completing the interviews (Rubin \& Rubin, 2013).

\section{Findings}

\section{Objective 1: Communication Patterns and Preferences}

Participants were asked questions about how they receive and seek out scientific livestock industry information and the demands they face for using and re-packaging that information for different audiences. Their job demands for communicating scientific livestock industry information ranged from needing descriptive, highly technical scientific information, to needing concise, nontechnical data summation that could be easily transferred to other audiences.

Two themes emerged as is related to this objective. The first was centered on their recommendations and preferences for using scientific information to communicate with their stakeholders, while the second was on how the study itself needed to potentially change before they would consider using it or sharing it with others.

\section{Theme 1.1: Improve the Variety, Usability, and Frequency of Communication}

In general, for more immediate or likely use of the NAHMS study reports, interviewees said they would like more formats than the PDF report of the information. However, they all said the PDF reports should still be available for deeper investigations or corroboration of any highlighted information. This is especially important for groups that do rely on in-depth information as well as shorter summaries, such as agricultural media. Agricultural journalists keep tabs on broader industry information while also reporting on more timely issues:

We watch everywhere from raw data on the market, like the hogs and pigs report, to APHIS, anything that would do with regulations, and proposed laws, legislation; anything that would change the way the hog producer raises pigs. We rely heavily on USDA's information, whether its raw data, it's information about regulations, whether they're changing rules or if it's just information they collect.

Journalists from agricultural media outlets commented on the need for press releases for current research, as well as fact sheets that provide a summary of findings, with important pieces of information highlighted. Any visuals or infographics are also helpful because such features attract more readers and aid audience understanding.

From there, I think the more relatable data to the audience is a must. If the information is practical and easy to understand, then it's a lot faster to turn the story. It just depends on the story I'm trying to develop. But if I want to do a quick online story, and they're trying 
to get a news release out that's quick and timely today, and it's basically a summary of that 80-page report, then I just want good quotes that I can build a story around. A good link to that 80 page that I can go hunt if I want to go hunt more information. But no, I don't want the 80-page report just handed to me in an email.

Within this theme, a subtheme emerged on the need to address the website usability of USDA and NAHMS. Almost all interviewees commented on the usability of the USDA website in general. Many recommended that the APHIS NAHMS page should be more prominent and include more program information - going back to communicating why certain research is important to all stakeholders. Those somewhat familiar with the website described how its organization of content was not entirely intuitive. Usability-wise, having to download/open PDF files to know what information is contained within them was described as "frustrating" by all interviewee types. Many emphasized the value of executive summaries and/or commented on the importance of highlighting the types of information audiences could find in the PDF files. One industry group discussed having the report information on PowerPoint slides that are easily found and downloadable from the website:

When I give presentations, I'll use USDA websites a lot. ...we have a lot of members that do presentations and things like that, either in meetings or to student events or to the public. It might be useful if they could put some of the charts and data on PowerPoint slides, so they could be used obviously with permission, a reference for NAHMS.

An issue for those less familiar (as for one livestock extension agent) with NAHMS study reports is they reported that they do not often come up in general search engine results unless keywords are specific enough. Beside the individual less familiar with the reports, others mentioned they had to remember to go directly to the website to find the information.

A consensus among those interviewed was that a "subscribe button" for NAHMS reports would be beneficial for upcoming research, as well as research that is being disseminated to target audiences. One swine industry journalist discussed how a "subscribe button" would help them in linking a NAHMS study report directly to an article they may write, which would help to increase credibility and help with research dissemination to producers:

Also, we use the information because we do get consumers through our site, but if we're using that kind of information, they see USDA as a good source. We would like to use those kinds of sources to not only build messages that consumers can find about pork, but also giving education to the hog producers so when they're having conversations outside of their business, they can use that data too. And they know how to get to it faster if it's on our site.

Besides improvements to the media channel variety and usability, many interviewees described how more interpersonal communication between organizational stakeholders and USDA APHIS representatives would help improve how government studies such as those done by NAHMS are received. Their recommendations included more conference research presentations, involvement in industry conferences as possible keynote speakers, writing research summaries for publication in industry media, and being involved in educational outreach panels. These types of interpersonal or in-person communication activities would also help bridge the gap between extension and USDA APHIS. One industry group representative went as far to say that those 
suggestions were just "the tip of the iceberg" when it came to possible engagements with stakeholders. Some interviewees said an increase in USDA APHIS presence at events like this would help to increase trust and could potentially bring in more study endorsements in the future. An agricultural journalist mentions that these face-to-face interactions would improve both stakeholder and producer perceptions of USDA APHIS:

They see the staff as individuals doing the right thing for the industry. And the more open communication USDA APHIS can be when they're at events, which I see this all the time. When they're at events and they're just being a person, and are having those conversations about the industry, they're well received. I think it's two ways and I see the producers really value their input, but I think the producers as farmers by nature, they're always gonna say, "It's good that you're going down this road with regulations or we understand you had to propose this or work on this rule but you're forgetting this." They're always gonna say, "don't forget the practical side of what that rule is." The more conversations and people being people. That all goes on I think the more the trust goes up with the producer.

Throughout this line of questioning on ways to improve communication, participants revealed how the AMU studies needed to potentially change before they would consider using it or sharing it with others, leading to the second theme in Objective 1.

\section{Theme 1.2: Issues with NAHMS Studies May Impede Willingness to Share/Use Reports}

The second theme centered on their desires for greater involvement in NAHMS studies' development, particularly in AMU data collection. This theme emerged within advocacy and industry group data. An interesting finding from a large advocacy group was their frustration with USDA APHIS as being biased towards large agricultural production. That bias was blamed on the group's lack of involvement in the NAHMS study development. In terms of the NAHMS AMU studies, this advocacy group also expressed frustration in the survey:

We were upset because the surveys lumped together treatment, control, and prevention. So, the question is, where do you draw the line with some of the other uses? The groups I work with really don't think you should use antibiotics for prevention where there's no signs of illness. We just think that's an inappropriate use. And so, if the reports don't capture that part of the use, and we have evidence from other countries that this could be $70 \%$ of the antimicrobial use, then we're missing data that we really need to have a conversation about how antibiotics are used in food animals. So, we're unhappy with not having that type of distinction.

Along with advocacy groups, industry organizations also felt that this distinction between treatment, control, and prevention was needed in NAHMS studies that deal with antibiotic usage. Other groups' representatives mentioned specific questions they would want addressed to make the study more useful:

In terms of what APHIS and USDA does in terms of antibiotic collection around food animals, our primary concern is to try to understand what are the reasons for most of the use? Why are we using antibiotics? For what specific purposes? And the next layer, if it would be possible for APHIS to do, is try to think then what are the contributing factors? What are the risk factors for higher use versus lower use? And if the studies could ever get that kind of information, that would be helpful for us. 
These issues seemed to negatively influence these industry and advocacy group participants' likelihood of disseminating the AMU studies' results. Participants said more time was needed for discussion to find common ground and establish industry trust. Related to this broader theme of a desire to be more involved, those in extension said agents are well-equipped to help promote the AMU and other NAHMS studies among livestock producers in their areas, which could help increase participation, particularly among smaller-sized farms.

Outside of looking at the broader picture of AMR, all participants agreed that the timeliness of the NAHMS studies were an issue, especially in the case of AMU. Although the majority were aware of the reasons as to why studies take a long period of time to develop, conduct, analyze, and report, the gap in years between the data collection and reporting is hard to contextualize. One recommendation from a neutral advocacy group was to focus on smaller data samples that could be disseminated quicker than the longer studies. This could help bridge gaps in the data and could potentially make results more actionable for industry professionals to disseminate to producers.

\section{Objective 2: Exploring Organizational-Stakeholder Relationship Quality}

To address this objective, questions focused on experiences in relationships (current and past) with federal agencies, particularly APHIS; how their own stakeholders view APHIS, barriers to building better relationships, and recommendations for improving relations. Five distinct themes emerged.

\section{Theme 2.1: Swine Industry Has Good Relationship Quality with APHIS}

Swine industry groups were extremely favorable of USDA APHIS, describing the relationship as "outstanding", "very close", "very trustworthy". All swine industry stakeholders were in agreement that they felt the relationship has improved in the past few years, especially in terms of making personal contacts for the organization. Most also felt their target audiences, ranging from policymakers to hog producers, had a high level of trust in USDA APHIS. This is a promising point, as industry organizations act as a liaison between USDA and producer segments, especially in terms of antibiotic usage as it relates to NAHMS studies. One organization representative described their thoughts:

I think everybody's on board with reducing antibiotic use. They've come to that conclusion the same way I think the human side did, as they're seeing not all antibiotics are working effectively so there were some issues with the resistance. They're also seeing an economic drain by excess using of antimicrobials. What they really want to see is, they want to see you reporting actual use versus 'I bought some and it's sitting on my shelf, doesn't mean I gave it to the pig. I stocked up my cabinet.' They want to see practical data because that's what the consumers are asking for. They also want to see real vested money, whether it's private or public research.

In terms of recommendations of improving relationships between swine industry groups and USDA APHIS, one included an opportunity to engage producers indirectly through statespecific organizations. Since APHIS must remain objective and not necessarily offer information geared towards informing production decisions, industry groups are needed as an intermediary 
information source, making them crucial in the process of disseminating government research. Swine industry group interviewees recommended that APHIS should form relationships with individual state swine production groups, not just nationally recognized organizations. They felt that building rapport with individual state swine organizations, especially in those states with a large hog population, has the potential to increase both promotion and dissemination of NAHMS studies.

\section{Theme 2.2: Cattle Industry Has Weaker Relationship Quality with APHIS}

Participants connected with the cattle industry described their relationships with APHIS as fraught with more frustration than those with the swine industry. This frustration stemmed from the AMU studies in particular and the perception that APHIS did not offer enough time or due diligence for conversations with industry representatives to further shape the survey. They described a key influence on them is cattle producers, who strongly value privacy and are sensitive to any talk or act that resembles government intrusion on their cattle business.

Cattle industry group participants mentioned that many cattle producers in their target audience already have distrust in government entities, but it had been exacerbated in recent years through a phenomenon described as "The Trump Effect" by a cattle industry journalist. Other interviewees with the cattle industry also mentioned the current political climate connected with President Donald Trump, which they described as empowering cattle producers' distrust in federal government because weakening federal government power was a platform of Trump's campaign. This general adversity to the government creates challenges for industry groups in any communication efforts of APHIS or any groups using USDA information in producer outreach efforts.

A representative from an agricultural media outlet focused primarily on cattle producers noted that even journalists' trust in USDA APHIS often falters due to the inability to reach a representative to find out more information on an industry issue. One representative noted frustration in wanting to get the facts straight on an issue, but not being able to successfully reach a USDA APHIS representative.

\section{Theme 2.3: Both Industries Desire More Front-End and Back-End Involvement in NAHMS Studies}

Both industries desired to see an increase industry involvement in the NAHMS survey design early and late in the process. One swine industry group participant stated:

One of the big problems that we have with communication or surveys in particular is you can go so far as to design the survey, but nobody ever talks about how you're going to report the results or what's going happen with the results. I think that's a big gap that we tried to express to the USDA, that the reporting of those results is as important or more important than actually conducting the survey. We have to understand what happens with those results.

Other swine industry group participants echoed similar thoughts, explaining that they appreciated being involved in the survey design but want to be further involved and informed on 
the dissemination of the study results. Cattle industry group participants had similar thoughts on improving the relationship with USDA APHIS through continual involvement with the NAHMS survey design:

"Room for improvement would be on the front end of projects in the development stage before things are finalized by APHIS and sent to OMB. It would be useful for us to be involved in that development process because if we have major concerns, I think it improves both organizations to get those out at the beginning and work through them, versus after the process is nearly completed, then asked for info. I think the only thing that could be improved is involving stakeholders in the process very early in the game, understanding that those conversations we would certainly be held confidential."

A criticism from industry groups that dealt with the AMU surveys' development was that some felt industry opinions were being dismissed in early stages of the process. These organizations felt more time was needed for discussion in finding common ground and establishing industry trust. Although, overall, industry organizations perceive USDA APHIS as a credible partner, many feel that greater transparency is needed.

\section{Theme 2.4: Interpersonal and Proactive Communication Could Bolster Relationship Quality}

In discussing relationship quality specifically, interviewees again brought up the importance of including the "human factor," meaning many members of these groups respond well to face-to-face interaction and "putting a face to a name." Beside conferences, interviewees' other recommendations included bi-annual meetings with industry stakeholders of all species in Washington D.C. Many groups, both cattle and swine, noted many key officials travel to D.C. regularly, or have satellite or main headquarters located there. These groups also offered that this type of meeting could be covered in their budget, possibly making events such as biannual meetings easier to achieve in a limited governmental budget through industry covered funding. Again, these groups noted the importance of USDA APHIS to the industry and want to be active participants in bridging the gap between organizations.

Interviewees also said another way to increase trust and credibility with producer facing organizations is for USDA APHIS to communicate why the research is important to stakeholders and be more proactive in their efforts. One industry organization put it this way: "It's important for producers to know why the research is being done and why it affects them. These studies should address the intent to improve sustainability, animal health production methods, and have science to back this all up."

Advocacy group interviewees noted that organizations need to be more proactive about reaching out to USDA APHIS, as knowledge creation is a constant flow between stakeholders, and not just APHIS' responsibility. These interviewees also discussed the importance of reaching a broader set of audiences with the NAHMS study reports and went back to how explaining the "why" of the studies would help attract those audiences. 


\section{Theme 2.5: Untapped and Valuable Partners for NAHMS Studies}

Broadening the types of stakeholders involved in shaping and communicating NAHMS studies was a key theme brought forward primarily from interviewees representing extension and an interview from the advocacy group that was more neutral on the issue of AMU in livestock production. Industry groups touched on this same idea when they described the importance of state-level stakeholder groups. To summarize, the interviewee from the more neutral group on AMU said:

I think there is a problem that maybe the agency hasn't been very proactive about trying to get a broader set of stakeholders in terms of, to provide input when they're developing surveys, or even making sure we see the results when they come out. I think all of those things the agency probably could do a better job of.

Interviewees with extension described their relationship with APHIS to be weak, but also described future potentials of strengthening relations. Interviewees representing extension said they view USDA APHIS as a trustworthy and credible source of information, but feel extension is overlooked as a stakeholder for NAHMS studies. They described how extension could act as an information intermediary, much like industry organizations do, in disseminating important research information.

These extension interviewees echoed industry group recommendations on the importance of making state-specific relationships. They suggested extension personnel be a point of contact to such ends. Gaining trust and credibility with local, county, and state experts could help USDA APHIS with all aspects of NAHMS studies, as extension groups can help foster relationships and positive perceptions among producers. When asked the best way to contact a state or county extension officer, most replied that a phone call directly to the agent would guarantee a response. Emails often get lost or forgotten, as many extension agents must navigate a job role that encompasses many responsibilities.

\section{Discussion and Implications}

The first set of conclusions and recommendations can be drawn from stakeholders' preferences for communicating federal scientific data on animal health and management practices. In order for research to be used and implemented, organizations should determine what type of information is valuable to the end-user and how that information is will eventually be used (Lavis et al., 2003). According to our results, key stakeholders would prefer NAHMS to offer study findings in multiple formats and in ways that improve access and usability, increase interpersonal communication efforts, and ensure stakeholder input on the types of data that would be valuable is included or addressed in some way. All-in-all a more complete communication package that includes: press releases customized for different types of media entities (general public, animal health media, commodity-focused media), e-mail newsletter people can subscribe to, shorter and more visual reports of key findings, infographics, and presentation slides with visuals and summaries. NAHMS can help improve their relationship with stakeholders by providing communication material that benefit the end-user (Hon \& Grunig, 1999). However, Lavis et al. (2003) noted that communication materials such as websites and newsletters are beneficial, but they do not replace the power of continuous interaction with stakeholders. This was echoed in our 
findings when stakeholders highlighted the importance of interpersonal communication and suggested NAHMS staff to attend webinars and presentations at relevant industry conferences or educational events hosted by agribusiness companies. Such tactics would not only increase reach and reach a wider array of stakeholders like advocacy organizations, journalists, and extension agents, but as our findings suggest, they would also increase the likelihood government research would be used, shared, and interpreted into best practices and policy. These results will help NAHMS, and other similar organizations, implement the KTT framework by revealing how the end-user prefers the reports to be disseminated (Ontario, 2016). Because government data is typically not interpreted or formulated into practical recommendations, the research findings need to reach those knowledge brokers in a meaningful way in order to have potential to create impact.

Beyond acting on those concrete recommendations in the findings to improve communication of the AMU and future NAHMS studies reports, there are many opportunities for relationship-building that will ultimately increase the dissemination of NAHMS research information and improve the science communication process. These findings hold more important implications for science communication of this nature.

Except the journalists, all interviewees expressed the importance of their involvement on the front- and back-end of NAHMS studies to ensure data contribute well to the global AMU/R conversation. They expect to see their influence in the final study, especially with measures on controversial production practices like AMU. These desires align with the KTE/KTT framework, which describes the importance of continued stakeholder input in the research process (Smith, 2014). Additionally, including stakeholders in the process could improve the relational quality dimension of commitment between NAHMS and their stakeholders. With stakeholders involved in the production of the NAHMS report, they may feel obliged to promote the research to their networks (Hon \& Grunig, 1999). In science communication, the notion of the science generators as experts and the public as information insufficient (i.e., the knowledge-deficit model) is a particularly alluring idea for policy design because the solution is straightforward and fits within the existing infrastructure of the education system (Simis, Madden, Cacciatore, \& Yeo, 2016). "Trust in scientific institutions, deference to scientific authority, and values, including religiosity and political ideology, represent murkier waters for building policy. These factors cannot be targeted through simple curriculum reform or exposure to new information" (Simis et al., 2016, p. 409). Community-based research has been recommended as a solution to helping address distrust in scientific institutions (Sims et al., 2016).

Before government-mandated agricultural research can move to an entirely communitybased model, there are communication approaches that would enhance the effectiveness in the aspects of the research these agencies do involve communities. In an invitation process, federal agencies should set clear expectations for stakeholders' participation and boundaries to protect the study's credibility. The boundaries will help develop control mutuality between the agency and participants, where the agency holds primary influence in an effort to provide objective results (Hon \& Grunig, 1999). Inviting them demonstrates trust and their participation illustrates their trust in the agency conducting the research. Once the study is finalized, following up with some explanation to those participating stakeholders on decisions made may help support relationship quality. They seem to want to feel heard, but some also expect to see their influence in the final study that is developed. Based on the analysis of this study's findings through the lens of the 
concepts of organizational-stakeholder relationship quality (Hon \& Grunig, 1999) and trust (Earle, 2010), we advise framing any follow-up communication around the following points:

1. Identify ways in which stakeholders did influence the study.

2. Express satisfaction from their contributions but when necessary, highlight the various stakeholder relationships the research sponsor must consider.

3. Highlight commitments made and future commitment to the relationships.

4. Point out the benefits of their insight and the benefits received (ultimately, the research and reports and the impact those had).

5. Reiterate the "why" of the study in terms of concern for their welfare.

6. Remind them of the boundaries of influence that are needed in order to ensure the study is credible and robust to attacks of biases by demonstrating inclusiveness and balancing of viewpoints.

Recall that calculative trust, which is trust based on the organization's actions and competence is more fragile than relational trust (Earle, 2010). When calculative trust seems to be broken, bolstering or reminding external stakeholders of relational trust is important, since it is more stable. To bolster relational trust, reinforce shared values and the research sponsor's intentions in communication with stakeholders.

Findings showed rebuilding relations and trust with cattle industry organizations is a felt need among the stakeholders interviewed, along with continuing to strengthen swine industry relationships. This could have been unique to this specific case study with the AMU survey. Still, lessons can be drawn and applied to cases when other research sponsors are faced with a need to repair relations to continue more successfully with future science communication efforts. With the cattle industry, targeted efforts should be made to highlight ways in which the AMU studies were developed with control mutuality and a communal relationship in mind (Hon \& Grunig, 1999). Although those in the cattle industry may currently feel dissatisfied with their relationship with APHIS, using communication to highlight the give and take and concern for the industry's welfare along with reigniting and demonstrating APHIS' commitment to the relationship could be key in disseminating the AMU report and for future studies (Hon \& Grunig, 1999). Additionally, outreach to state-level cattle organizations are likely necessary for the AMU studies since current relationships with national organizations will need time and effort to build.

Because of fractured relationships with the cattle industry, those stakeholders may use select data to protect market interests and preferred ideologies and sow doubt on the credibility of the study (National Academies, 2017). Arguably, animal activist and certain consumer advocacy groups may do the same. In fact, any government data is subject to weaponization in pursuit of advocacy groups' agendas. Federal agencies should ensure good communication with journalists and those in extension to help inoculate against such attacks. Scientists and media are trusted more when science intersects controversy (Brewer \& Ley, 2013). Notably, however, if those groups feel they were a part of the study development process, they would be less likely to engage in attempts to discredit the research, and may be more likely to help share it (Smith, 2014).

Finally, we note extension and state-based farmer and rancher groups are untapped partners for this federal agency. Not only can extension serve as a knowledge broker, which is a pivotal role in the KTE/KTT framework, but if pursued, they would help enhance and strengthen 
stakeholder relationships since many agents have closer connections with state agricultural commodity organizations. Therefore, we recommend focusing on extension to help reach the statebased groups that were also mentioned in the findings. Extension agents prefer to receive notice when studies are launched or reports are ready since they may not routinely check a federal agency's website or may find the website difficult to navigate. Offering a listserv for email notifications, hosting a webinar, and/or presenting at a conference are ways to reach those in Extension. They place high value on phone calls. Although calling extension agents would certainly take more time than sending out mass emails or hosting events, the payoff of the effort is likely to be higher over other channels of communication, according to those we interviewed in this study.

\section{Limitations and Future Research}

This study's focus on NAHMS studies, and their AMU studies in particular, as a case study through which to explore a science communication process and its products means some caution should be taken in considering the transferability of these results to other contexts. Conducting future qualitative research with small farm/ranch-focused organizations, niche producer-focused organizations, and independent veterinarians could reveal richer findings this study was unable to capture. To better assess the details of design and usability of science communication materials these interviewees said they prefer, conducting studies in which these stakeholders could evaluate materials directly is a logical next step. 


\section{References}

Abrams, K. M., Zimbres, T., \& Carr, C. (2015). Communicating sensitive scientific issues: the interplay between values, attitudes, and euphemisms in communicating livestock slaughter. Science Communication, 37(4), 485-505. https://doi.org/10.1177/1075547015588599

American Veterinary Medical Association. (2020). Antimicrobial use and antimicrobial resistance pet owner FAQ. https://www.avma.org/antimicrobial-use-and-antimicrobialresistance-pet-owner-faq

Brewer, P. R., \& Ley, B. L. (2013). Whose science do you believe? Explaining trust in sources of scientific information about the environment. Science Communication, 35(1), 115-137.

Center for Food Integrity. (2018). A dangerous food disconnect: When consumers hold you responsible but don't trust you. http://www.foodintegrity.org/research/consumer-trustresearch/current-research

Charles, D. (2016, Dec. 22). Despite pledges to cut back, farms are still using antibiotics. National Public Radio. https://www.npr.org/sections/thesalt/2016/12/22/506599017/despite-pledges-to-cut-backfarms-are-still-using-antibiotics

Druckman, J. N. (2015). Communicating policy-relevant science. Political Science \& Politics, 48(Special Issue 1), 58-69.

Farm Foundation. (2016). Stewardship of antimicrobial drug use in food-producing animals. https://www.farmfoundation.org/webcontent/Stewardship-of-medically-importantantimicrobial-drug-use-in-food-animals-1927.aspx

Hon, L. C., \& Grunig, J. E. (1999). Guidelines for measuring relationships in public relations. The Institute for PR. http://www.aco.nato.int.libproxy.lib.unc.edu/resources/9/conference\%202011/guidelines _measuring_relationships[1].pdf

International Food Information Council Foundation. (2016). 2016 Food and Health Survey. https://www.foodinsight.org/articles/2016-food-and-health-survey-food-decision-2016impact-growing-national-food-dialogue

Johnson, B. B., \& Slovic, P. (1995). Presenting uncertainty in health risk assessment: Initial studies of its effects on risk perception and trust. Risk Analysis, 15(4), 485-494.

Joslyn, S. L., \& LeClerc, J.E. (2012). Uncertainty forecasts improve weather related decisions and attenuate the effects of forecast error. Journal of Experimental Psychology: Applied, 18(1), 126-140. https://doi.org/10.1037/a0025185 
Ontario. (2016). Knowledge translation and transfer (KTT). Retrieved Knowledge Translation and Transfer (KTT). (n.d.). http://www.omafra.gov.on.ca/english/research/ktt/indexktt.html

Lavis, J. N., Robertson, D., Woodside, J. M., McLeod, C. B., \& Abelson, J. (2003). How can research organizations more effectively transfer research knowledge to decision makers?. The Milbank Quarterly, 81(2), 221-248.

Lee, T. L., Reinhardt, C., Schwandt, E., \& Thomson, D. (2017). Producer opinions on antibiotic use in the beef industry. Kansas Agricultural Experiment Station Research Reports, 3(1). https://doi.org/10.4148/2378-5977.1341

Marshall, C., \& Rossman, G. B. (2014). Designing qualitative research. Sage publications.

National Academies of Sciences, Engineering, and Medicine. (2017). Communicating science effectively: A research agenda. Washington, DC: The National Academies Press. http://doi.org/10.17226/23674

PEW Charitable Trusts. (2016). FDA Policies on antibiotic use in food animals: Key elements and how to strengthen them. http://www.pewtrusts.org/en/research-and-analysis/factsheets/2016/05/fda-policies-on-antibiotic-use-in-food-animals-key-elements-and-how-tostrengthen-them

PEW Charitable Trusts. (2018). Antibiotic resistance project. http://www.pewtrusts.org/en/projects/antibiotic-resistance-project

Robinson, O. C. (2014). Sampling in interview-based qualitative research: A theoretical and practical guide. Qualitative Research in Psychology, 11(1), 25-41.

Rubin, H. J., \& Rubin, I. S. (2011). Qualitative interviewing: The art of hearing data. Sage.

Smith, M. F. (2014). Knowledge transfer and exchange. In: Michalos A.C. (eds) Encyclopedia of Quality of Life and Well-Being Research. Springer, Dordrecht.

Simis, M. J., Madden, H., Cacciatore, M. A., \& Yeo, S. K. (2016). The lure of rationality: Why does the deficit model persist in science communication? Public Understanding of Science, 25(4), 400-414. https://doi.org/10.1177/0963662516629749

USDA APHIS. (2010). Collecting vital information on animal health. https://www.aphis.usda.gov/animal_health/nahms/downloads/NAHMS_brochure.pdf

USDA APHIS. (2015). Proposed initiatives from the USDA Antimicrobial Resistance Action Plan.

https://www.aphis.usda.gov/animal_health/nahms/amr/downloads/ProposedInitiatives.pdf

USDA (2019a). “Antimicrobial Use and Stewardship on U.S. Feedlots, 2017”. USDA-APHISVS-CEAH-NAHMS. Fort Collins, CO. https://www.aphis.usda.gov/animal_health/nahms/amr/downloads/amu-feedlots_1.pdf 
USDA. (2019b). “Antimicrobial Use and Stewardship on U.S. Swine Operations, 2017”. USDAAPHIS-VS-CEAH-NAHMS. Fort Collins, CO. https://www.aphis.usda.gov/animal_health/nahms/amr/downloads/amu-swine.pdf

U.S. Food and Drug Administration. (2017). Fact sheet: Veterinary Feed Directive final rule and next steps. https://www.fda.gov/AnimalVeterinary/DevelopmentApprovalProcess/ ucm449019.htm

World Health Organization. (2018). Antimicrobial resistance. http://www.who.int/en/newsroom/fact-sheets/detail/antimicrobial-resistance 